\title{
An Application to Continuous Probability Distribution
}

\section{Nirmala Kasturi}

Abstract: First part of the paper is the brief description of previous work about estimating one of the distributions developed by smoothing techniques of the histograms and second part of the paper is the application of the distribution.

Key Words: Random variable, continuous probability distribution, arrival rate, density function, histograms, frequency.

\section{INTRODUCTION}

Part 1: Random variable of interest is "Staying only $n$ number of arrivals in the system in particular time interval". The arrivals stay in the system while going in queue to service and questioning for some data in the system (before leaving the system). Instead of asking "how many arrivals take place in a particular time interval (Poisson)", we ask for "how likely the system have $\mathrm{n}$ number of arrivals in particular time interval". Since X is continuous, the PDF should be a function. We have to make inferences about this unknown function. We have surveyed for a considerable period of time. We plot the histograms for different number of arrivals from which we find the density curves [2].

In general for the chosen random variable "Staying only $n$ number of persons in the system in particular interval" the p.d.f. is

$f(x)=\left\{\begin{array}{l}\frac{e^{-\lambda x}(\lambda x)^{n} \lambda}{n !} \text { when } x \geq 0 \\ 0 \text { otherwise }\end{array}\right.$

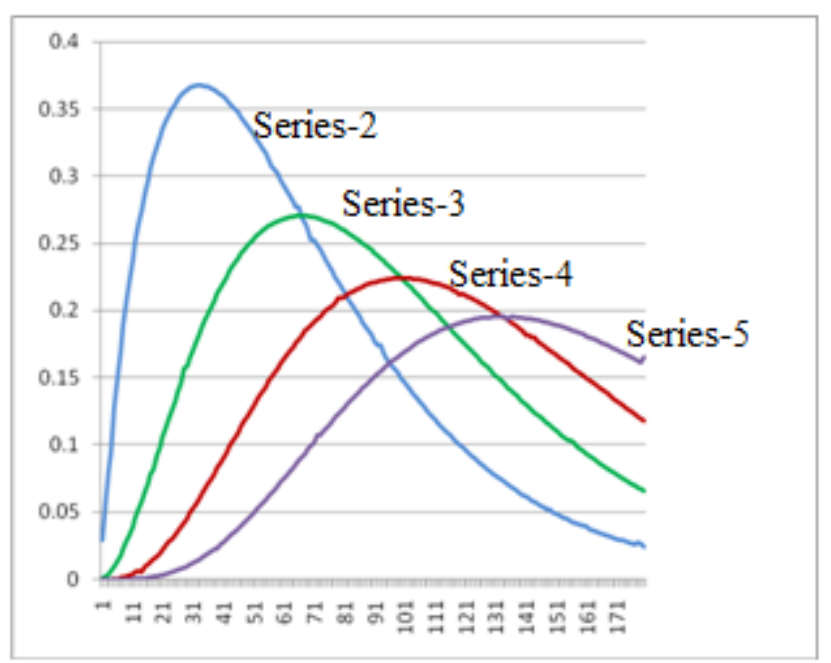

FIGURE - 1

Revised Manuscript Received on December 06, 2020.

Nirmala Kasturi, Research Scholar, Department of Computer Science and Engineering, GITAM (Deemed to be University), and Visakhapatnam, India.
Series 2 represents the probability density function graph when $\mathrm{n}=1$.

Series 3 represents the probability density function graph when $\mathrm{n}=2$.

Series 4 represents the probability density function graph when $n=3$.

Series 5 represents the probability density function graph when $\mathrm{n}=4$.

$\mathrm{X}$ - Axis represents time; $\mathrm{Y}$ - represents $\mathrm{f}(\mathrm{x})$.

PART 2: Studying efficiency of queuing system will be useful to make suggestions to management to take good decisions in an optimized way. The efficiency in any queuing system can be measured by no. of arrivals accumulated at the system and queue.

As a result of part 1 , by using density function, we can find probability of accumulating number of arrivals in the particular interval. Now it is useful to compare two queuing systems. By using this we can say that in which queuing system there is more probability of more number of customers accumulated in less time

If we consider the random variable that "the no. of people accumulated at the queue in particular interval" then by using p.d.f. function.

$f(x)=\left\{\begin{array}{l}\frac{e^{-\lambda x}(\lambda x)^{n} \lambda}{n !} \text { when } x \geq 0 \\ 0 \text { otherwise }\end{array}\right.$

Now this probability of no. of people accumulated in the queue in same time interval for any two queuing system can be compared. The queuing system where we get more probability for accumulating same no. of customers in same time interval, that queuing system referred as less efficient queuing system. We consider this time interval for the comparison i.e. $\left[0, \frac{n}{\lambda}\right]$. A survey was conducted in village and city branches of the same bank. Let us take number of customers $\mathrm{n}$ up to $\mathrm{n}=1,2,3,4$.

$\lambda_{1}=$ Arrival rate of village bank $=0.007$ customers/sec.

$\lambda_{2}=$ Arrival rate of city bank $=0.03$

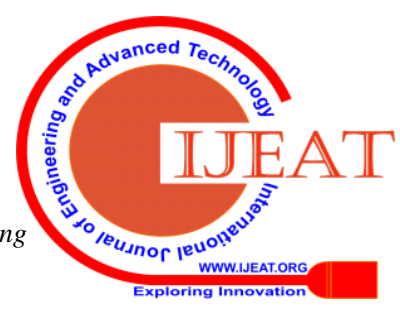


customers/sec.

The calculation of the probabilities of accumulating $n$ number of people in the same time interval for both queueing systems.

The density function is

$f(x)=\frac{e^{-\lambda x}(\lambda x)^{n} \lambda}{n !}$

For $\mathbf{n}=1:$ Case 1: For the city branch bank.

We take time interval $\left[0, \frac{n}{\lambda}\right]=[0,33]$

For $n=1$ the p.d.f. function is

$f(x)=\frac{e^{-\lambda x}(\lambda x) \lambda}{1 !}$

$\int_{0}^{33} e^{-(0.03) x}(0.03 x) \cdot 0.03 x d x$

$\mathrm{u}=\mathrm{x}$

$d u=d x$

$\mathrm{V}=e^{-(0.03)}$

$\int v d v=\frac{e^{-0.3 x}}{-0.03}$

$\int_{0}^{33} e^{-(0.03) x}(0.03 x) \cdot 0.03 x d x$

$=(0.03)^{2} \int_{0}^{33} e^{-(0.03) x} x d x$

$=\left(-(0.03 x+1) e^{-0.03 x}\right)_{0}^{33}$

$=0.260562$

\section{Case 2:}

For village branch bank:

For $n=1$ the p.d.f. function is $f(x)=\frac{e^{-\lambda x}(\lambda x) \lambda}{1 !}$

We take the same time interval as in urban

branch bank

$\int_{0}^{33} e^{-(0.007) x}(0.007 x) 0.007 d x$

$\left[-(0.007 x+1) e^{-0.007 x}\right]_{0}^{33}$

$=0.0229067$

$\therefore$ The probability that the no. of people $(n=1)$

accumulated at the queue in some time is more

for the city branch which we can refer as less

efficient.

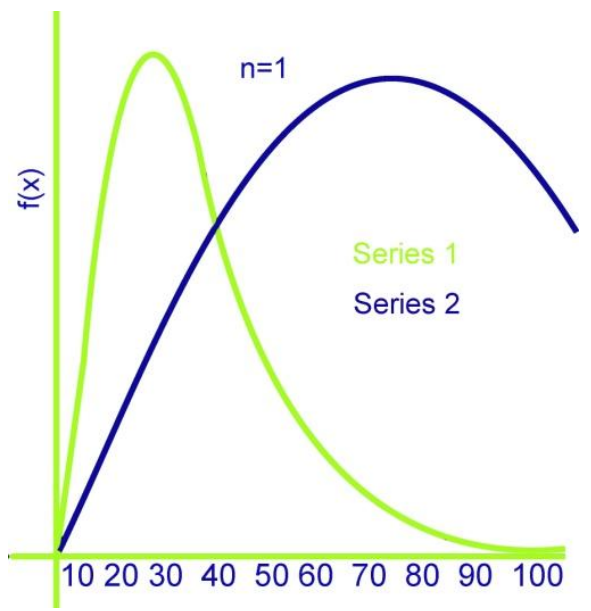

Figure - 2

Series 1 represents $n=1$ number of arrivals accumulating at city branch in particular time interval.

Series 2 represents $n=1$ number of arrivals accumulating at village branch in particular time interval.

For $\mathbf{n}=2$ : Case 1: For city branch bank.

For $\mathrm{n}=2$ the p.d.f. function is

$$
f(x)=\frac{e^{-\lambda x}(\lambda x)^{2} \lambda}{2 !}
$$

We take time interval up to the neighborhood of

$\frac{n}{\lambda}$ 
i.e. $\left[0, \frac{n}{\lambda}+1\right]=[0,67]$

$\int_{0}^{67} f(x) d x$

$=\int_{0}^{67} \frac{e^{-\lambda x}(\lambda x)^{2} \lambda}{2} d x$

$=\int_{0}^{67} \frac{e^{-0.03 x}(0.03 x)^{2}(0.03) d x}{2 !}$

$=\frac{(0.03)^{3}}{2} \int_{0}^{67} e^{-0.03 x}(0.03 x)^{2} d x$

$=\left[-\left(0.00045 x^{2}+0.03 x+1\right) e^{-0.03 t}\right]_{0}^{67}$

$=\left[-(2.02005+0.03 \times 67+1) e^{-(0.03) 67}+1\right]$

$=\left[-5.03005 \times e^{-2.01}+1\right]$

$=0.326030$

Case 2 For village branch bank

We take the same time interval [0.67]

For $n=2$ the p.d.f. function is

$f(x)=\frac{e^{-\lambda x}(\lambda x)^{2} \lambda}{2 !}$

$=\int_{0}^{67} f(x) d x$

$=\int_{0}^{67} \frac{e^{-\lambda x}(\lambda x)^{2} \lambda}{2 !} d x$

$=\int_{0}^{67} \frac{e^{-(0.007) t}(0.007 \times 67)^{2}(0.007)}{2 !} d t$
$=-(0.00897+0.04087+0.0874635) e^{-0.469}+0.087446$

$=-(0.1373035) e^{-0.469}+0.087446$

$=-(0.1373035) 0.625627+0.087446$

$=-0.085732+0.087446$

$=0.00171320$

The number $(n=2)$ of people accumulated at the queue in same time interval is more for the city branch bank that village branch bank.

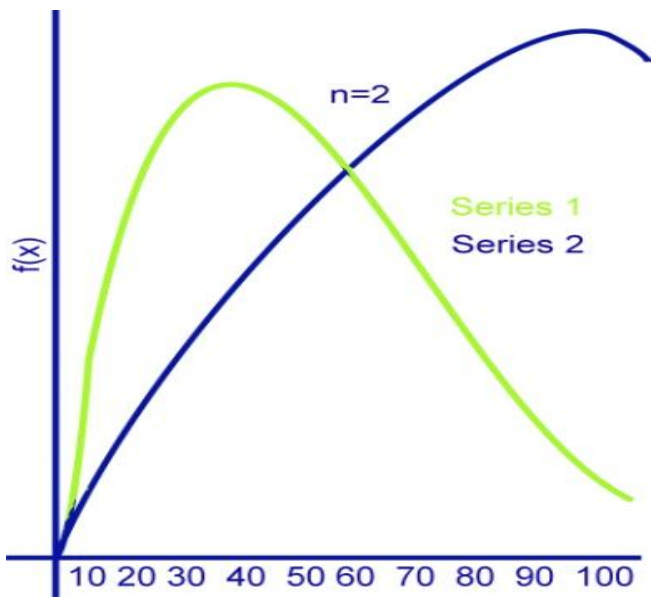

Figure - 3

Series 1 represents $\mathrm{n}=2$ number of arrivals accumulating in city branch in particular time interval.

Series 2 represents $n=2$ number of arrivals accumulating in village branch in particular time interval.

For $n=3$ Case 1: for city branch bank

For $\mathrm{n}=3$ the p.d.f. function is

$f(x)=\frac{e^{-\lambda x}(\lambda x)^{3} \lambda}{3 !}$

We consider the interval up to in the

neighborhood of $\frac{n}{\lambda}$ i.e., $\left[0, \frac{n}{\lambda}+1\right]=[0,100]$

$\int_{0}^{100} f(x) d x$ 


$$
\int_{0}^{100} \frac{e^{-\lambda x}(\lambda x)^{3} \lambda}{3 !} d x
$$

$$
\int_{0}^{100} \frac{e^{-0.03 x}(0.03 x)^{3}}{3 !} 0.03 d x
$$

$$
\frac{(0.03)^{4}}{3 !} \int_{0}^{100} e^{-0.03 x} x^{3} d x
$$

\section{$-1.209327891+1.8685=0.6591721093$}

We got the probability of accumulating 3

customers in the queue in the time period of

$[0,100]$ is $0.659 / 72$ for urban branch bank

Case 2: For village branch bank

For $n=3$ the p.d.f. function is

$$
f(x)=\frac{e^{-\lambda x}(\lambda x)^{3} \lambda}{3 !}
$$

We consider the same interval $[0,100]$

$$
\begin{aligned}
& \int_{0}^{100} \frac{e^{-\lambda x}(\lambda x)^{3} \lambda}{3 !} d x \\
& \int_{0}^{100} \frac{e^{(-0.007) x}(0.007 x)^{3} 0.007}{3 !} d x
\end{aligned}
$$$$
\frac{(0.007)^{4}}{6} \int_{0}^{100} e^{(-0.007) x} x^{3} d x
$$

We got the probability of accumulating 3 customers in the queue in the time period of $[0,100]$ is 0.0063 for village branch bank

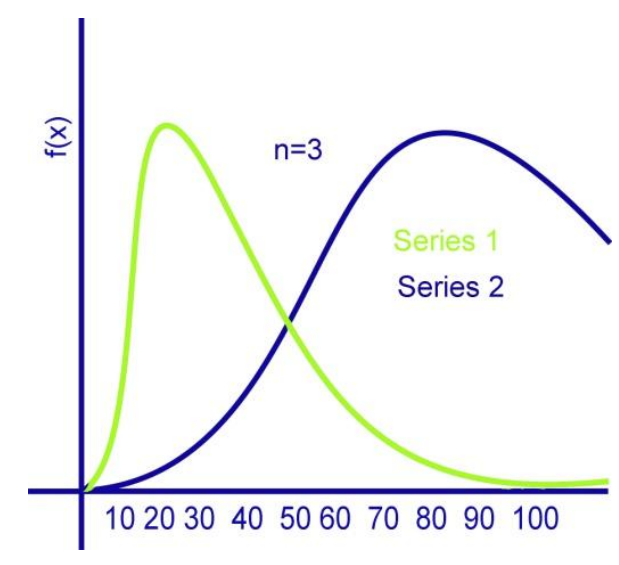

Figure - 4

Series 1 represents $(\mathrm{n}=3) \mathrm{n}$ number of customers accumulating at the city branch in particular time interval. Series 2 represents $(\mathrm{n}=3) \mathrm{n}$ number of customers accumulating at the village branch in particular time interval.

\section{For $n=4:$ Case 1}

\section{For city branch Bank}

We take time interval up to the neighborhood of $\frac{n}{\lambda} i . e\left[0, \frac{n}{\lambda}+1\right]=[0,133]$

$$
\int_{0}^{133} f(x) d x
$$

For $n=4$ the p.d.f. function is

$$
\begin{gathered}
f(x)=\frac{e^{-\lambda x}(\lambda x)^{4} \lambda}{4 !} \\
{\left[-\left(5.6938 \times 10^{-8} x^{3}+2.4402 \times 10^{-5} x^{2}+0.00697 x+0.99\right) e^{-0.007 x}\right]_{0}^{100}} \\
\int_{0}^{133} \frac{e^{-0.03 x}(0.03 x)^{4} 0.003}{24} d t
\end{gathered}
$$

$=-(0.98969)+0.996$

$$
=0.0063
$$

$$
\frac{(0.03)^{3}}{24} \int_{0}^{133} e^{-0.03 t} x^{4} d t
$$




\begin{tabular}{|c|c|}
\hline$=0.587232+0.96$ & $\begin{array}{l}\text { customers in queue in the time period of [0.133] } \\
\text { is } 0.3400 \text { for village branch bank. }\end{array}$ \\
\hline
\end{tabular}

We got the probability of accumulating 4

customers in the queue in the time period of

$[0,133]$ is 0.3727 for city branch bank.

\section{Case 2: For village branch bank}

We consider the same interval [0.133] as in city branch bank case

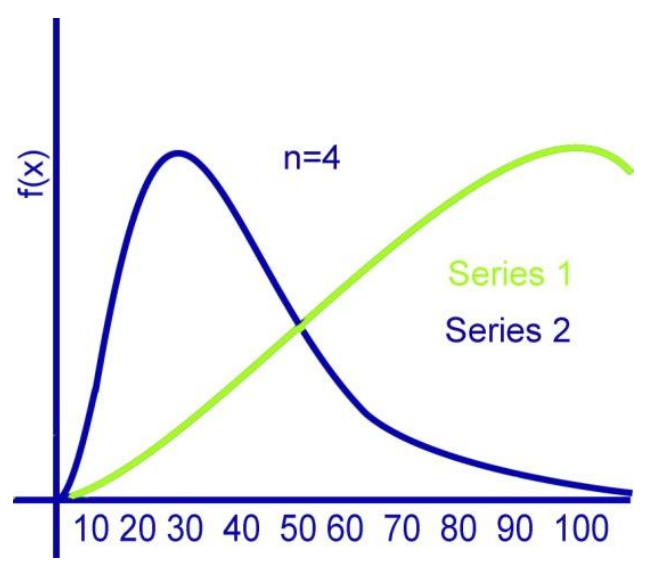

i.e. $[0.133]$

Figure - 5

For $n=4$ the p.d.f. function is

$$
\begin{aligned}
& f(x)=\frac{e^{-\lambda x}(\lambda x)^{4} \lambda}{4 !} \\
& \int_{0}^{133} f(x) d x
\end{aligned}
$$$$
\int_{0}^{133} \frac{e^{-\lambda x}(\lambda x)^{4} \lambda}{4 !} d x
$$$$
\int_{0}^{133} \frac{e^{-(0.007 x)}(0.007 x)^{4} 0.007}{4 !} d x
$$$$
=\frac{(0.007)^{5}}{24} \int_{0}^{133} e^{-0.007 x} x^{4} d x
$$$$
\text { REFERENCES }
$$$$
=\left[-\left(9.604 \times 10^{-9} x^{4}+5.488 \times 10^{-8} x^{3}+2.352 \times 10^{5} x^{2}+0.00672 x+0.96\right) e_{1 .}^{-0.007 x}\right]_{\text {Daisuke Nakezat }} e^{133}
$$

\section{CONCLUSION}

This paper proposed the application of the p.d.f. function.

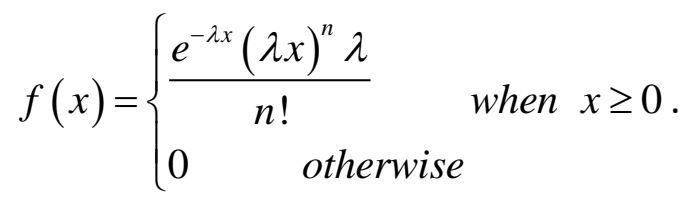

measuring the probability of accumulating $\mathrm{n}$ number of customers we made the inference that the quantum of work is not equal and may vary in different locations. Therefore, we can conclude an employee in a rural branch is prone to more idle time. Various graphs and data authenticate the same.

1. 006 Daisuke Nakezat $\delta$, Demitriidso Bertsimas The distributional Little's law and its applications, (with D.Nakazato), Operations Research, 43, 2, 298-310, MIT, 1995 .

2. Nirmala Kasturi, A Continuous Probability Distribution on Departures; Article Accepted by IJERD Journal. Ref. ID AB712013.

$=\left[-(2.19) e^{-0.007 x}\right]_{0}^{133}$

$=0.34$

3. Hamdy Taha: Operations research An Introduction, seventh edition, pearson education.

4. James M Thomson and Donald Gross; Fundamentals of Queueing theory, Third addition, 2002: Wiley series.

5. Janus Sztrik, Queueing theory and its applications; A personal view by Proceedings of the 8th International conference on Applied Informatics, Eger, Hungary, Jan 27-30, 2010, Vol.1, PP.9-30.

6. Jeffrey Herrman: A survey of Queueing theory Applications in Healthcare, Samue Fomundam ISR Technical Report 2007-24. 


\section{An Application to Continuous Probability Distribution}

7. J-P Cletch, D.M.Noctor, J.C.Manock, G.W.Lynott and F.E.Bader; Surface Mount Assembly failure statistics and failure free items AT\&T Bell laboratories, $44^{\text {th }}$ ECTC, Washington, D.C, May 1-4 1994, PP.293-297.

8. Michael D. Peterson, Dimitris J. Bertsimas, Amedeo R. Odoni; MIT, Models and algorithms for Transient Queueing Congestion at Airports, Management science, volume 41, 1279-1295, 1995.
26. X. Papaconstantinou, On the exact steady state solution of the Ek/C2/s queue, European Journal of Operations Research, 37(2), 272-287, 1988.

27. [27] J Keilson, D, Nakazato, H, Transient and busy period analysis of the GI/G/1 queue as a Hilbert factorization problem, Journal of Applied Probability, 28, 873-885, 1991.

9. Demitriics BertsimasAn analytic approach to a general class of G/G/s queuing systems, Operations Research, 38, 1, 139-155, MIT 1990.

10. S.D. Sharma; Operations research, Fourteenth addition, 2003, Kedarnadh and Ramnadh and co. publishers.

11. W. Weibull "A statistical distribution function of wide applicability" Journal of applied Mechanics, September 1951, pp 293-297.

12. R.Luus and Jammer; Estimation of parameters in 3 parameter Weibull probability distribution functions, $10^{\text {th }}$ international workshop on Chemical Engineering Mathematics, Budapet, Hungary, August 18-20 (2005).

13. Patric O'Conner, Reliability Engineering, $5^{\text {th }}$ Edition, 2012, Wiley Series.

14. William W. Hines, Douglas C. Montgomerry, David M.Goldsman, Connie M. Borrer, probability and Statistics in Engineering, Fourth Edition, Wiley Series.

15. Vijay K. Rohatgi, A.K.Md. Ehsanes Saleh, An Introduction to Probability And Statistics, Second Edition, Wiley Series.

16. Kishore S. Trivedi, Probability \& Statistics with Reliability, Queueing And Computer Science Applications, Second Edition, Wiley Series.

17. Ravindran, Phillips, Solberg, Operations Research principles and practice, Second Edition, Wiley series.

18. R.Sree parimala, S.Palaniammal Bulk Service Queueing Model With Services Single and Delayed Vacation, International Journal of Advances in Science and Technology(IJAST), Vol 2, Issue 2, June 2014.

19. J. D. C. Little, "A Proof for the Queuing Formula: Operations Research, vol. 9(3), 1961, pp. 383-387, doi: 10.2307/167570.

20. M. Laguna and J. Marklund, Business Process Modeling, Simulation and Dsign, Pearson Prentice Hall, 2005.

21. Gamarnik, On the Undecidability of Computing Stationary Distributions and Large Deviation Rates for Constrained Random Walks, Mathematics of Operations Research, 2007, Vol. 32, 257 265.

22. Gamarnik, Katz, On Deciding Stability of Multiclass Queueing Networks under Buffer Priority Scheduling Policies, Mathematics of Operations Research, 2009, Vol. 19, 2008-2037.

23. Ajeet Kumar Pandey, Srinivas Panchangam, Jessy George Smith, Safety analysis of Automatic Door operation for Metro Train : A case study. $\quad 9^{\text {th }}$ International conference on Heterogeneous Networking for quality, reliability Robustness, January 11-12-2013, Greater Noida, India.

24. Wallace Agiel, Christian Asave, Modeling and Analysis of Queueing Systems in Banks, International Journal of Scientific Technology, Volume 4, Issue 7, July 2015.

25. T.L. Pap and L. Leiszner, The use of Queueing Theory for planning automated analytical systems, Journal of Automated Chemistry, volume 9, No. 2 (April- June 1987), p.p 87-91. 